\title{
Fast Detection of 5-Hydroxymethylfurfural in Dulce de Leche by SPE-LC-MS
}

\author{
Sebastian Imperiale ${ }^{1}$ (D) $\cdot$ Ksenia Morozova $^{1}$ (D) $\cdot$ Giovanna Ferrentino $^{1}$ (D) $\cdot$ Md Rizvi Alam $^{1} \cdot$ Matteo Scampicchio $^{1}$ (D)
}

Received: 1 March 2021 / Accepted: 9 July 2021 / Published online: 6 August 2021

(c) The Author(s) 2021

\begin{abstract}
This research paper investigates the use of 5-hydroxymethylfurfural (5-HMF) as marker for the heat treatment of spreadable dairy creams (dulce de leche, DL). The proposed method applies solid-phase extraction (SPE) with final analysis by liquid chromatography coupled with high-resolution mass spectrometry (SPE-LC-MS). The method was successfully applied to analyze spreadable dairy creams prepared by hot melt extrusion using different heating temperatures from 100 to $130{ }^{\circ} \mathrm{C}$. The concentrations of 5-HMF correlated linearly with the applied temperatures, with a signal response in the range from 0.5 to $100 \mu \mathrm{M}\left(R^{2}=0.9997\right)$. The limit of detection (LOD) was $1.54 \pm 0.03 \mu \mathrm{M}$ with a precision of $1.77 \%$. The results were compared with the analysis of 5-HMF in spreadable dairy creams using reference methods for the determination of 5-HMF in milk products. These methods mainly employed acid digestion and derivatization as pre-processing steps and determined 5-HMF spectrophotometrically and via HPLC-UV. These resulted in higher LOD (2.99 and $2.01 \mu \mathrm{M})$ and less precision (4.44 and $2.09 \%$ ) compared to the proposed method. Furthermore, the proposed pre-processing procedure was faster by omitting the acid digestion and derivatization steps and by employing SPE.
\end{abstract}

Keywords Spreadable dairy creams $\cdot$ LC-MS $\cdot$ Solid-phase extraction $\cdot$ Maillard reaction $\cdot$ Thermal processing

Spreadable dairy creams are a popular snack food, especially within children. A typical example of spreadable dairy creams is represented by dulce de leche (DL), a brown and sweet cream obtained by the extensive heating of milk, when mixed with sugars and bicarbonate. During heating, the chemical reactions occurring between amino acids and reducing sugars lead to the formation of Maillard reaction products (Maillard 1912; Jousse et al. 2002; Mundt and Wedzicha 2003; Bellarde 2005). Depending on the extent of the reaction, the heating profile, and the amount and type of ingredients used, the Maillard reaction can give rise to several chemical products, such as furosine, 5-hydroxymethylfurfural (5-HMF), pyridosine, maltosine, or maltol (van Boekel 1998; Malec et al. 1999, 2005; Francisquini et al. 2016; Francisquini et al. 2018). These can affect in different degrees the resulting colour formation (i.e. browning) and flavour development (Pinto and Wolfschoon-Pombo 1984; Pavlovic et al. 1994; van Boekel 2006; Newton et al. 2012).

Ksenia Morozova

ksenia.morozova@unibz.it

1 Faculty of Science and Technology, Free University of Bozen-Bolzano, Piazza Università 5, 39100 Bolzano, Italy
Because the Maillard reaction greatly affects the sensorial characteristics of the final product, there is a certain interest to estimate the extent of the reaction developed during processing. For this purpose, several markers have been proposed. Among those, furosine (Resmini et al. 1990, 2003) and 5-HMF (Keeney and Bassette 1959) are the most studied. Especially, 5-HMF is a highly used marker to determine the extent of the Maillard reaction during heating (Troise 2018).

5-HMF is an intermediate organic compound derived from the dehydration of certain sugars during heating. The formation of 5-HMF may occur at any $\mathrm{pH}$, temperature, and water activity, but its formation is favoured by high temperatures, alkaline $\mathrm{pH}$, and high water activity levels. In these conditions, the Maillard reaction occurs at a much higher rate (Morales and van Boekel 1998; Labuza and Baisier 1992; Rodriguez et al. 2016; d'A Francisquini et al. 2019). For this reason, the determination of 5-HMF is an important quality index in products that may easily undergo overprocessing like DL (van Boekel 1998; Pischetsrieder et al. 1999; Kowalski et al. 2013; Ritota et al. 2017).

To date, 5-HMF has been detected in several types of food, including spirits and honey (Murkovic and Bornik 
2007; Shapla et al. 2018; Escriche et al. 2008), wine and other alcoholic beverages (Serra-Cayuela et al. 2013), fruit juices and vinegars (Gürkan and Altunay 2015), coffee (Murkovic and Pichler 2006), breakfast cereals (Garcia-Villanova et al. 1993), and different types of bread (RamírezJiménez et al. 2000). 5-HMF is also determined in milk products, such as lactose-hydrolysed and protein-fortified milk (Aktağ et al. 2019), partially reconstituted skim milk powder (Haghani-Haghighi et al. 2019), and infant formulas (Tsai and Kao 2012).

The determination of 5-HMF in milk products is usually performed using spectrophotometric methods after digestion of samples under acidic conditions and in some cases after derivatization with thiobarbituric acid (TBA) (Keeney and Bassette 1959; Czerwonka et al. 2020). The formation of 5-HMF is typically measured using ultraviolet absorbance (UV) at $284 \mathrm{~nm}\left(18000 \mathrm{M}^{-1} \mathrm{~cm}^{-1}\right)$, because of the strong absorption of furfural-like compounds (Gürkan and Altunay, 2015), or at $443 \mathrm{~nm}$ for the TBA derivative (Keeney and Bassette 1959). In recent years, also high-performance liquid chromatography (HPLC) gained importance for the detection of 5-HMF in food (Teixidó et al. 2006, 2008; Serra-Cayuela et al. 2013). For HPLC analysis of 5-HMF, typically liquid-liquid extraction is necessary, especially in complex matrices.

A common challenge in the analysis of products with a complex sample matrix is that many compounds naturally present in foods may also interfere with the light absorption of 5-HMF. Although acid digestion with eventual derivatization is commonly used to obtain a stronger absorption of furfural compounds, these procedures are rather time consuming and require extensive work from the operator. Furthermore, when the chromatographic resolution is poor, or the sample matrix is too complex, interferences may adversely affect the quantification of 5-HMF. Such possible lack of accuracy in the determination of 5-HMF has recently received more attention than in the past because of some cytotoxic (Nässberger 1990), genotoxic (Severin et al. 2010), and tumoral effects (Durling et al. 2009) associated with some 5-HMF derivatives, like 5-chloromethyl and 5-sulfidemethylfurfural. Although the subject is debated (Abraham et al. 2011), the possible safety concerns related to the consumption of 5-HMF have driven the need to develop alternative methods for its quantitation. This applies even in samples containing high concentration of interferences.

The above-mentioned drawbacks can be overcome by using solid-phase extraction (SPE). Specifically, with the use of SPE, sample interferences can be reduced and the resolution of the compounds of interest can be increased. In addition, the SPE procedure can be easily automatized leading to an increase in the number of samples that can be analyzed. As an example, SPE has been used by Resmini et al. (1990) as clean-up step of dairy products to analyze furosine via HPLC-UV for the assessment of the damage induced by the heat. The application then of high-resolution mass spectrometry (MS) as detection technique can exploit its high accuracy to detect 5-HMF by using its exact mass and $\mathrm{MS}^{2}$ spectrum.

For the reasons above, this study proposes a rapid method to determine the content of 5-HMF in DL samples based on liquid chromatography coupled to mass spectrometry (LC-MS) after SPE. Different DL samples subjected to increasing thermal treatments were analyzed. The results were compared with the analysis of 5-HMF in DL using previous methods for the determination of 5-HMF in milk products which employ acid digestion and derivatization as pre-processing steps (Keeney and Bassette 1959; Francisquini et al. 2018; Czerwonka et al. 2020).

\section{Materials and Methods}

\section{Chemicals and Reagents}

5-Hydroxymethylfurfural (5-HMF) was purchased from Sigma-Aldrich (Steinheim, Germany) at purity higher than 99\%. Trifluoroacetic acid (TFA) was purchased from Alfa Aesar, methanol from Honeywell, concentrated hydrochloric acid solution, trichloroacetic acid (TCA), oxalic acid, 2-thiobarbituric acid (TBA), $\mathrm{NaCl}, 8 \mathrm{~mol} \mathrm{~L}^{-1} \mathrm{NaOH}$ solution, diethyl ether, and LC-MS grade acetonitrile were purchased from Sigma-Aldrich and not purified further. For HPLC methods, ultrasonicated Milli-Q water was employed.

\section{Heated Milk}

Heated milk samples were prepared and analyzed to determine the 5-HMF content during heating. Pasteurized semiskimmed ( $1.6 \%$ fat) milk was obtained from the local market. Milk samples (10 $\mathrm{mL}$ each) were transferred to glass vials (Pyrex vials with screwcap) and placed in a thermostatic water bath at $80^{\circ} \mathrm{C}$. After $1,2,3$, and $4 \mathrm{~h}$, the vials were removed from the water bath and immediately placed on ice. Pasteurized milk without further heat treatment was used as control.

\section{Dulce de Leche Preparation}

For the formulation of dulce de leche, pasteurized whole milk obtained from the local market, fructose, and sodium bicarbonate were used. The samples were prepared by mixing $100 \mathrm{~mL}$ of milk, $40 \mathrm{~g}$ of fructose, and $0.5 \mathrm{~g}$ of sodium bicarbonate. Sodium bicarbonate was added to fasten the browning reaction and to prevent protein coagulation by 
increasing the $\mathrm{pH}$ of the mixture above the isoelectric point of the proteins, such as the casein micelles.

\section{Extrusion Cooking of Dulce de Leche (DL)}

DL samples were prepared by hot melt extrusion with a co-rotating twin screw extruder with a screw diameter of $11 \mathrm{~mm}$ and a length to diameter ratio (L/D) of 40 (Pharma 11 Twin-screw Extruder, Thermo Scientific ${ }^{\mathrm{TM}}$ ). To prepare the DL samples, the screw speed was set to $140 \mathrm{rpm}$ while the mixture was pumped to the extruder with a peristaltic pump at constant flow rate of $0.10 \mathrm{~mL} \mathrm{~min}^{-1}$. The temperature along the barrel was constant (temperatures: 100, 110, 120 , and $130{ }^{\circ} \mathrm{C}$ ). DL samples were produced at each of the four different temperatures. After each run, the extruder was stopped, opened, cleaned, and assembled again. Then, the temperature for the following condition was set to run the next experiment. For each experiment, the samples were collected when both the flow rate and the torque values were stable for at least $2 \mathrm{~min}$.

\section{Spectrophotometric Determination of 5-HMF}

For comparison, 5-HMF content was also measured by spectrophotometric analysis according to Keeney and Bassette (1959) with some modifications. For each temperature, one sample was used, resulting in a total number of four samples. Each sample was extracted in triplicate as follows. Five grams of DL was diluted with $10 \mathrm{~mL}$ of water. Then, $2.5 \mathrm{~mL}$ of the dilution was mixed with $2.5 \mathrm{~mL}$ of oxalic acid solution $\left(0.3 \mathrm{~mol} \mathrm{~L}^{-1}\right)$ and $2.5 \mathrm{~mL}$ of trichloroacetic acid (TCA) solution $(40 \% \mathrm{w} / \mathrm{v})$ and filtered through filter paper. Four millilitres of the filtrate was then mixed with $1 \mathrm{~mL}$ 2-thiobarbituric acid (TBA- $0.05 \mathrm{~mol} \mathrm{~L}^{-1}$ ) and heated at $40{ }^{\circ} \mathrm{C}$ for $30 \mathrm{~min}$ in a thermostatic bath. After cooling, the samples were analyzed at $443 \mathrm{~nm}$ using a spectrophotometer (Infinite M nano + 200Pro, Tecan Group Ltd., Switzerland) against a blank containing water treated under the same conditions as the samples. The quantification was performed against a calibration curve of 5-HMF standard solutions $(4.2-33.6 \mu \mathrm{M})$ containing TCA $(16 \% \mathrm{w} / \mathrm{v})$ and TBA $\left(0.01 \mathrm{~mol} \mathrm{~L}^{-1}\right)$ and incubated in a thermostatic bath at $40{ }^{\circ} \mathrm{C}$ for $50 \mathrm{~min}$.

\section{Sample Preparation Procedure for Analysis by Liquid Chromatography}

The same number of samples as before were extracted in triplicate. The DL samples were extracted according to Czerwonka et al. to determine 5-HMF using HPLC-UV (Czerwonka et al., 2020). In short, $1 \mathrm{~g}$ of DL sample was diluted with $10 \mathrm{~mL}$ of water. Three millilitres of diluted sample were mixed with $1.5 \mathrm{~mL}$ oxalic acid solution $(0.3 \mathrm{~mol}$ $\left.\mathrm{L}^{-1}\right)$. After $20 \mathrm{~min}, 1.5 \mathrm{~mL}$ TCA solution $(40 \%$, w/v) was added, stirred, and the mixture filtered through a filter paper. Two millilitres of the filtrate was mixed with $1 \mathrm{~mL}$ of saturated $\mathrm{NaCl}$ solution and extracted three times with diethyl ether $(20,10,10 \mathrm{~mL})$. The organic fractions were collected and combined, and the solvent was evaporated under nitrogen stream at temperature of $40{ }^{\circ} \mathrm{C}$ (Multivap 8, LabTech S.r.l., Milano, Italy). The residue was dissolved in $1 \mathrm{~mL}$ methanol, and $1-\mathrm{mL} \mathrm{NaOH}$ solution $\left(1 \mathrm{~mol} \mathrm{~L}^{-1}\right)$ was added and brought to $10-\mathrm{mL}$ volume with water. The mixture was filtered with a $0.45-\mu \mathrm{m}$ syringe filter prior to injection into the HPLC system.

\section{Sample Preparation Procedure Using SPE}

The DL samples were processed following the procedure by Resmini et al. (1990) in triplicate with some modifications. Ten millilitres of the heated milk samples and the control were each transferred into $15-\mathrm{mL}$ Falcon tubes. One gram of each DL sample was diluted with $30 \mathrm{~mL}$ of deionized water and transferred into 50-mL Falcon tubes. The samples were mixed and acidified with hydrochloric acid solution $\left(0.3 \mathrm{~mol} \mathrm{~L}^{-1}\right)$ to $\mathrm{pH} 4.5$ and centrifuged at $9000 \mathrm{rpm}$ at $4{ }^{\circ} \mathrm{C}$ for $10 \mathrm{~min}$. The supernatant containing the watersoluble fraction and the whey proteins was collected and directly subjected to SPE omitting the acid hydrolysis for $23 \mathrm{~h}$ foreseen by Resmini et al. Then, $0.5 \mathrm{~mL}$ of sample was loaded on a preconditioned $\left(15 \mathrm{~mL} 1: 2 \mathrm{MeOH} / \mathrm{H}_{2} \mathrm{O}\right.$ v/v) C18 SPE cartridge ( $V=6 \mathrm{~mL}$, Thermo Sci.) and eluted with 3-mL hydrochloric acid solution $\left(3 \mathrm{~mol} \mathrm{~L}^{-1}\right)$ until dryness of the cartridge using air flow with an automated SPE system (GX-271 Aspec, Gilson Italia S.r.l, Italy). One millilitre of the eluate was dried under nitrogen flow at room temperature (MultiVap 8, LabTech S.r.1., Milano, Italy) and dissolved in $1 \mathrm{~mL}$ of $5 \%$ acetonitrile in deionized water and analyzed by LC-HRMS. The standard error was calculated as standard deviation divided by the square root of number of repetitions.

\section{Liquid Chromatography Coupled to High-Resolution Mass Spectrometry (LC-HRMS)}

The determination of 5-HMF in samples extracted by SPE and by the procedure suggested by Czerwonka et al. (2020) was performed by HPLC-UV coupled to HRMS. The system consisted of a Q-Exactive Orbitrap HRMS instrument (Thermo Fisher Scientific) coupled to an Ultimate 3000 UHPLC instrument (Thermo Fisher Scientific) with $\mathrm{UV}-\mathrm{Vis}$ detector. The separation of the compounds was done at a flow rate of $1 \mathrm{~mL} \mathrm{~min}{ }^{-1}$ with a LUNA C8 LC column $(150 \mathrm{~mm} \times 4.6 \mathrm{~mm}$ i.d., $5 \mu \mathrm{m}, 100 \mathrm{~A}$, phenomenex $)$ with a $\mathrm{C} 8$ security guard cartridge system (phenomenex). The mobile phase consisted of a combination of solvents A (water with addition of $0.1 \%$ trifluoroacetic acid $v / v$ ) and $\mathrm{B}$ 
(acetonitrile). The gradient was set as follows: $5 \% \mathrm{~B}(\mathrm{v} / \mathrm{v})$ for $7.5 \mathrm{~min}$, then from 5\% B to $95 \% \mathrm{~B}$ at 8 min, hold until $8.5 \mathrm{~min}$ then to $5 \% \mathrm{~B}$ at $9 \mathrm{~min}$ followed by a re-equilibration step (5\% B) from 9 to $10 \mathrm{~min}$. After each sample, a wash step with a blank (phase A) was introduced with the same chromatographic set-up as before, but with a different gradient: from $5 \% \mathrm{~B}$ at $0 \mathrm{~min}$ to $95 \% \mathrm{~B}$ at $1 \mathrm{~min}$, hold $95 \%$ until $3 \mathrm{~min}$, from $95 \%$ at $3 \mathrm{~min}$ to $5 \% \mathrm{~B}$ at $4 \mathrm{~min}$ followed by a re-equilibration step (5\% B) from 4 to $7 \mathrm{~min}$. For Full-MS analysis, the mass spectrometer was operated in positive ionization mode using the following conditions: sheath gas at 20 (arbitrary units), aux gas at 10 (arbitrary units), aux temperature $50{ }^{\circ} \mathrm{C}$, spray voltage at $\pm 3.5 \mathrm{kV}$, capillary temperature at $320{ }^{\circ} \mathrm{C}$, and RF S-lens at $65 \%$. The mass range selected was from 50 to $750 \mathrm{~m} / \mathrm{z}$ with a Full-MS set resolution of 35,000 at $\mathrm{m} / \mathrm{z} 200$, AGC target at $2 \times 10^{5}$, and max. injection time of $50 \mathrm{~ms}$. The $\mathrm{MS}^{2}$ measurements of the selected ions were performed with a resolution of 17,500 and AGC target at $5 \times 10^{5}$. Correlation of chemical compounds relative abundances and integration of the area under each peak (HPLC-MS EIC integrations) was done using Compound Discoverer 3.1 software (Thermo Scientific, Milano, Italy).

\section{Liquid Chromatography with Diode Array Detector (HPLC-DAD) for Acquisition of Absorption Spectra}

The determination of the absorption maxima of detected compounds was performed using a 1260 Infinity HPLC instrument coupled to diode array detector (DAD) (Agilent Technology). For chromatographic separation, the same gradient conditions were employed as for LC-HRMS. Flow rate of $1 \mathrm{~mL} / \mathrm{min}$ with a LUNA C8 LC column and security guard were used. The mobile phases included solvents A (water with addition of $0.1 \%$ trifluoroacetic acid $\mathrm{v} / \mathrm{v}$ ) and $\mathrm{B}$ (acetonitrile), and the following gradient: $5 \% \mathrm{~B}(\mathrm{v} / \mathrm{v})$ for $7.5 \mathrm{~min}$, then from $5 \% \mathrm{~B}$ to $95 \% \mathrm{~B}$ at $8 \mathrm{~min}$, hold until $8.5 \mathrm{~min}$ then to $5 \% \mathrm{~B}$ at $9 \mathrm{~min}$ followed by a re-equilibration step $(5 \% \mathrm{~B})$ from 9 to $10 \mathrm{~min}$.

\section{Results and Discussion}

\section{Identification of 5-HMF}

Figure 1 shows the extracted ion chromatogram of 5-HMF obtained from the analysis of a dulce de leche sample by HPLC-MS after sample preparation using SPE. No acid digestion or derivatization of the sample was needed. The chromatogram is characterized by an intense peak with a retention time of $5.85 \mathrm{~min}$. The identification was obtained by comparing its retention time, UV spectrum $\left(\lambda_{\max }=284 \mathrm{~nm}\right.$ obtained by HPLC-DAD. Figure 1, inset), and MS spectrum with those reported in previous studies

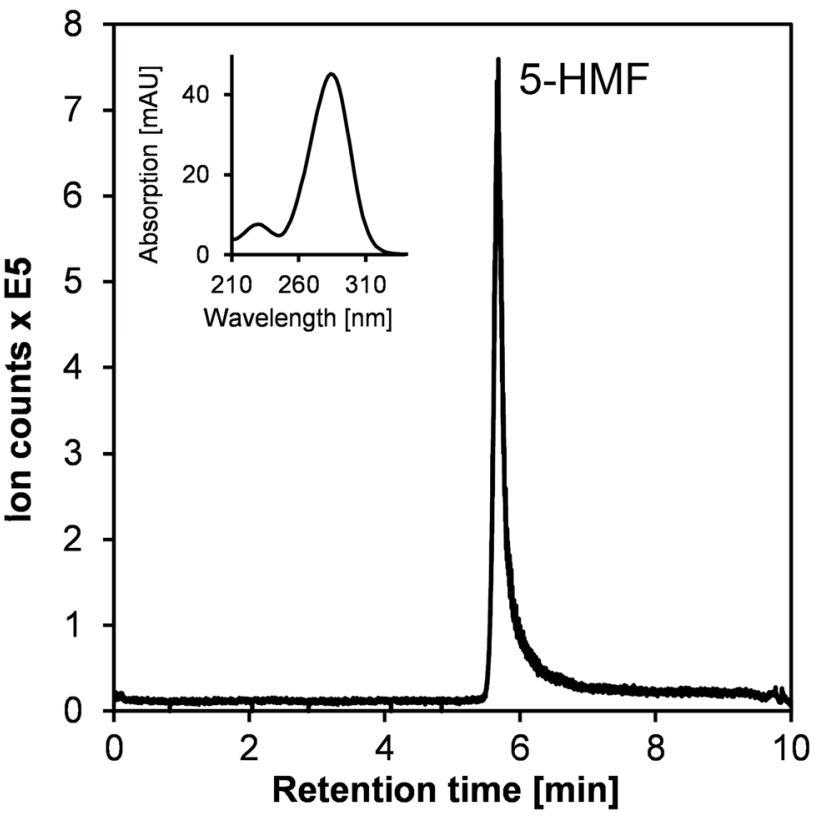

Fig. 1 Extracted ion chromatogram of $[\mathrm{M}+\mathrm{H}]^{+} \mathrm{m} / \mathrm{z}=127.0392$ obtained for the DL sample produced at $130{ }^{\circ} \mathrm{C}$ and processed with the proposed SPE-LC-MS method. Inset: absorption spectrum of $5-\mathrm{HMF}$ with retention time of 5.85 min obtained with HPLC-DAD (absorption maximum at $\lambda_{\max }=284 \mathrm{~nm}$ )

(Keeney and Bassette 1959; Serra-Cayuela et al. 2013; Larrañaga et al. 2016). The absorption maximum and retention of the peak matched those of 5-HMF. Furthermore, a 5-HMF standard was injected to confirm the identity of the peak. The standard peak demonstrated the same properties.

Final confirmation was given from the analysis of the full-MS and $\mathrm{MS}^{2}$ spectrum (Fig. 2). The quasi-molecular ion $[\mathrm{M}+\mathrm{H}]^{+}$of $5-\mathrm{HMF}(\mathrm{m} / \mathrm{z}$ of 127.0392) was found with a mass accuracy of $\Delta m_{i}=-1.57 \mathrm{ppm}$ for the compound eluting at $5.85 \mathrm{~min}$ and the standard. Characteristic fragments like $\mathrm{m} / \mathrm{z}[\mathrm{M}+\mathrm{H}]^{+}$109.0290, 81.0343, and 53.0395 matched those of the 5-HMF standard. The origin of such fragments is consistent with the loss of water $\left[\mathrm{M}+\mathrm{H}-\mathrm{H}_{2} \mathrm{O}\right]^{+}$ $(\mathrm{m} / \mathrm{z} 109.0290)$ and the successive losses of $\mathrm{CO}$ groups $\left[\mathrm{M}+\mathrm{H}-\mathrm{H}_{2} \mathrm{O}-\mathrm{CO}\right]^{+}\left(\mathrm{m} / \mathrm{z}\right.$ 81.0343) and $\left[\mathrm{M}+\mathrm{H}-\mathrm{H}_{2} \mathrm{O}-\right.$ $\mathrm{CO}-\mathrm{CO}]^{+}(\mathrm{m} / \mathrm{z}$ 53.0395). A similar MS/MS spectrum was previously reported using low-resolution mass spectrometry (Serra-Cayuela et al. 2013), and the fragmentation of furan5-(diethoxymethyl)-2-furanmethanol was described by $\mathrm{Hu}$ and $\mathrm{Li}$ (2011). The concentration of 5-HMF was proposed as index of heat treatment.

\section{Validation of 5-HMF for the Assessment of Heat Treatments of DL Samples}

The analytical performance of the proposed SPE-LC-MS method to determine 5-HMF was next investigated. For the 
validation of the method, an analytical standard of 5-HMF was injected at increasing concentrations, measured in triplicate. The choice of mass resolution of 35,000 in Full-MS and 17,500 in $\mathrm{MS}^{2}$ was a compromise between the best sensitivity and the highest resolution. Figure 3 a shows the ion count signal for increasing concentrations of 5-HMF. For concentrations of 5-HMF in the range between 0.5 and $100 \mu \mathrm{M}$, the signal trend is linear $\left(R^{2}\right.$ of 0.9998$)$, with a sensitivity of $5.1 \pm 0.2 \times 10^{6}$ ion counts $\min \mu \mathrm{M}^{-1}$ and a precision of $1.8 \%$ (Table 1). The limit of detection (LOD) was $1.54 \pm 0.03 \mu \mathrm{M}$ and the limit of quantitation (LOQ) was $5.12 \pm 0.09 \mu \mathrm{M}$.

Matrix effects of the sample were investigated by the standard addition method. When a DL sample was spiked with known concentrations of 5-HMF (from 0.2 to $27 \mu \mathrm{M}$, Fig. 3a), the resulting signal response gave $R^{2}=0.9995$ and slope not significantly different from the calibration with standard solutions ( $p=0.32>0.05$, inset Fig. 3a). The calibration curve obtained with the standard solutions
Fig. 2 MS spectra of 5-HMF obtained by LC-HRMS. (a) Full-MS spectrum at 5.85-min retention time of DL sample processed with SPE-LC-MS. Identification of 5-HMF with a quasi-molecular ion $[\mathrm{M}+\mathrm{H}]^{+}$ $\mathrm{m} / \mathrm{z}=127.0392$. (b) Confirmation of 5-HMF with full-MS spectrum of its analytical standard. (c) $\mathrm{MS}^{2}$ spectrum of 5-HMF in DL obtained with higher-energy collisional dissociation (HCD) at $33.33 \mathrm{eV}$. Fragments of m/z 109.0290, 81.0343, and 53.0395 with proposed structures

Fig. 3 Validating 5-HMF as marker for thermal treatment in DL. (a) Extracted ion chromatogram of m/z 127.0392. Spiking DL with increasing concentrations of 5-HMF standard (standard addition method). Inset: calibration using 5-HMF standard solutions ( $\boldsymbol{\Delta}$ ) and standard addition method (SAM, 口); (b) UV-Vis chromatogram at $280-\mathrm{nm}$ retention time of DL samples produced at different temperatures
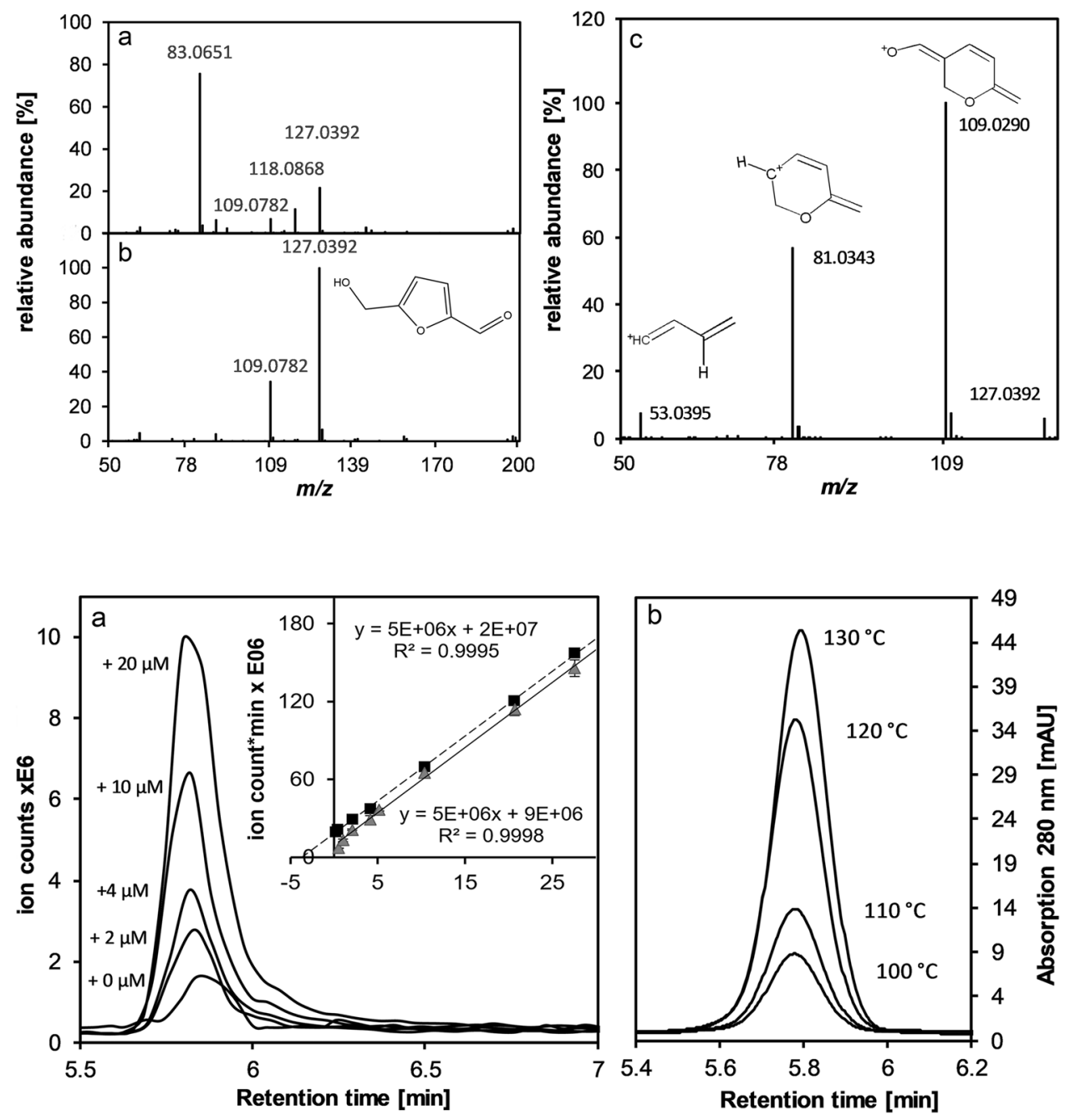

\begin{tabular}{|c|c|c|c|c|c|}
\hline Method & Linearity $R^{2}$ & Precision & Sensitivity & $\begin{array}{l}\text { LOD } \\
{[\mu \mathrm{M}]}\end{array}$ & $\begin{array}{l}\text { Correlation with } \\
\text { SPE-LC-MS } \\
\left(R^{2}\right)\end{array}$ \\
\hline SPE-LC-MS & 0.9998 & $1.77 \%$ & $\begin{array}{l}5.1 \times 10^{6} \\
\text { ion counts } \min \mu \mathrm{M}^{-1}\end{array}$ & $1.54 \pm 0.03^{*}$ & 1 \\
\hline HPLC-UV & 0.9997 & $2.09 \%$ & $11.70418 \mu \mathrm{AU} \min \mu \mathrm{M}^{-1}$ & $2.01 \pm 0.02^{*}$ & 0.9997 \\
\hline TBA Derivative UV & 0.9948 & $4.44 \%$ & $0.017 \mathrm{AU} \min \mu \mathrm{M}^{-1}$ & $2.99 \pm 0.62^{*}$ & 0.970 \\
\hline
\end{tabular}

*Significantly different, $p<0.05$
Table 1 Correlation between the proposed SPE-LC-MS method and the reference methods employed for the determination of 5-HMF in DL 
could therefore be used to quantify the 5-HMF in the DL samples.

\section{Comparing the Proposed SPE-LC-MS Method with Reference Methods}

The proposed method for 5-HMF detection in DL with SPELC-MS was compared with reference methods for the determination of 5-HMF in dairy products. First, the proposed method was compared with the spectrophotometric method by Keeney and Bassette (1959), which employs acid digestion and derivatization with TBA. 5-HMF standard solutions with increasing concentrations were subjected to acidic digestion and derivatization and determined via spectrophotometer. The concentrations of 5-HMF linearly correlated between both methods $\left(R^{2} 0.970\right.$, Table 1$)$. Compared to the proposed SPE-LC-MS method, the spectrophotometric method has a significantly higher LOD of $2.99 \pm 0.62 \mu \mathrm{M}$ and a LOQ of $14.79 \pm 2.07 \mu \mathrm{M}(p=0.0004<0.05)$. The sensitivity was $0.017 \mathrm{AU} \min \mu \mathrm{M}^{-1}$ and the precision $4.44 \%$.

Next, the proposed SPE-LC-MS method was compared with the method by Czerwonka et al. (2020), which determines 5-HMF in milk using HPLC-UV after acidic digestion and liquid-liquid extraction. To assess the analytical performance of the HPLC-UV system, a calibration curve with increasing concentrations of 5-HMF was constructed. Compared to the proposed SPE-LC-MS method, 5-HMF determination via HPLC-UV resulted in a significantly higher LOD of $2.01 \pm 0.02 \mu \mathrm{M}$ and a LOQ of $6.69 \pm 0.05$ $\mu \mathrm{M}(p=0.014<0.05)$. A precision of $2.09 \%$ and a sensitivity of $11.70418 \mu \mathrm{AU} \min \mu \mathrm{M}^{-1}$ were obtained. The correlation with the SPE-LC-MS method was $R^{2}=0.9997$ as reported in Table 1.

\section{Assessing the Heat Treatments of DL Samples}

Finally, the SPE-LC-MS method was used to estimate the level of heat treatment in DL produced by hot melt extrusion. Figure $3 \mathrm{~b}$ shows the effect of the increased temperature during DL production on the resulting formation of 5-HMF. A linear increase of 5-HMF intensity with increasing temperature was observed. The concentration of the analyzed 5-HMF in all the samples was calculated against the previously obtained calibration curve using LC-MS. Table 2 reports the quantification of 5-HMF in each sample, after peak integration. The measured concentrations of 5 -HMF ranged from $15.13 \pm 0.12 \mu \mathrm{mol} \mathrm{g}^{-1}$ with a standard error of 0.07 in DL samples prepared at $100{ }^{\circ} \mathrm{C}$ to $30.40 \pm 0.30 \mu \mathrm{mol} \mathrm{g}^{-1}$ with a standard error of 0.17 in the samples prepared at $130{ }^{\circ} \mathrm{C}$.

All DL samples were also pre-processed according to Keeney and Bassette (1959) with digestion using TCA and derivatization with TBA and finally measured via spectrophotometer. For all DL samples, the concentration of 5-HMF measured with the reference method gave similar results to the proposed SPE-LC-MS method (Table 2). The concentrations of 5-HMF linearly increased in both methods with the increasing temperatures applied during DL production.

In addition, the DL samples were extracted following the procedure by Czerwonka et al. (2020) and the concentrations of 5-HMF determined using the HPLC-UV system. However, the peak of 5-HMF in the samples extracted with this procedure including acid digestion and liquid-liquid extraction was not well resolved due to the presence of other interferences making the final quantification of this compound difficult (Fig. 4). Processing the DL samples with the proposed SPE method, however, resulted in no interferences in UV.

Finally, the suitability of the method was also tested for milk heated under milder thermal conditions. 5-HMF in milk can be formed either via Amadori products of the Maillard reaction through enolization or through lactose degradation and isomerization (Czerwonka et al. 2020). When milk samples were heated at $80^{\circ} \mathrm{C}$ for increasing time, even up to $4 \mathrm{~h}$, the resulting 5-HMF concentration was always below the limit of detection using the SPE-LC-MS method. Thus, the proposed procedure seemed especially suitable for the analysis of dairy products extensively treated with high temperatures. This result was expected as 5-HMF is usually not used directly as marker for heated milk. In order to enable the 5-HMF detection, milk is usually subjected to acid digestion and derivatization with TBA (Keeney and Bassette 1959; Francisquini et al. 2018; Haghani-Haghighi et al., 2019), or acidic digestion followed by liquid-liquid extraction (Czerwonka et al. 2020) as described in the compared reference methods. However, in the case of DL, the
Table 2 5-HMF concentrations in DL samples prepared by hot melt extrusion at different temperatures measured by the reference spectrophotometric method (with TBA-derivative by Keeney and Bassette 1959) and the proposed SPE-LC-MS method

\begin{tabular}{|c|c|c|c|c|c|c|}
\hline \multirow{3}{*}{$\begin{array}{l}\text { Temperature } \\
{\left[{ }^{\circ} \mathrm{C}\right]} \\
100\end{array}$} & \multicolumn{6}{|c|}{ 5-HMF $\left[\mu \mathrm{mol} \mathrm{g}{ }^{-1} \mathrm{DL}\right]$} \\
\hline & \multicolumn{3}{|c|}{$\begin{array}{l}\text { Spectrophotometric method with TBA- } \\
\text { derivative }\end{array}$} & \multicolumn{3}{|c|}{ Proposed SPE-LC-MS method } \\
\hline & 14.64 & \pm & 1.21 & 15.12 & \pm & 0.13 \\
\hline 110 & 16.13 & \pm & 0.89 & 17.97 & \pm & 0.44 \\
\hline 120 & 29.23 & \pm & 0.32 & 24.10 & \pm & 2.31 \\
\hline 130 & 37.72 & \pm & 2.20 & 30.40 & \pm & 0.31 \\
\hline
\end{tabular}




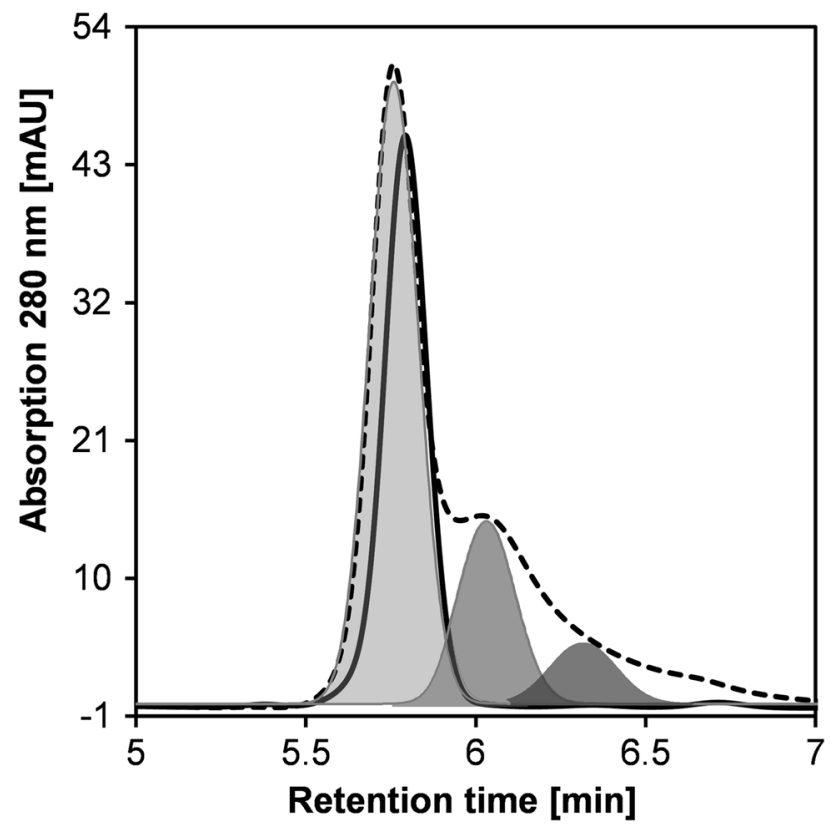

Fig. 4 UV-Vis chromatogram at 280-nm absorption of DL obtained at $130{ }^{\circ} \mathrm{C}$ processed with SPE (solid line) and after liquid-liquid extraction without SPE (dashed line). Shaded peaks: deconvolution of the signal obtained from DL without SPE (dashed line)

proposed SPE-LC-MS procedure allowed a faster and better clean-up of the samples for the detection of 5-HMF. The method took less than 45 min to pre-process the samples compared to the pre-processing steps of the reference methods, which take over $60 \mathrm{~min}$.

\section{Conclusions}

This study proposes a rapid method to assess the thermal treatments of spreadable dairy creams like DL using SPELC-MS to directly detect 5-HMF as marker. The proposed procedure allowed a faster and better clean-up of the DL samples for the detection of 5-HMF compared to reference methods, which employ spectrophotometric detection. Although using a spectrophotometer results in a faster analysis of 5-HMF, the proposed method allowed chromatographic separation of the 5-HMF peak, resulting in a better resolution. Additionally, for DL, the use of SPE allowed the removal of interferences, otherwise present when employing liquid-liquid extraction. Finally, the use of HRMS ensured the accurate identification of the marker in DL samples. The LC-HRMS system allowed to determine 5-HMF in the concentration range from 0.52 to $103 \mu \mathrm{M}$ with a limit of detection of $1.54 \pm 0.03 \mu \mathrm{M}$ and a limit of quantitation of $5.12 \pm 0.09 \mu \mathrm{M}$, precision of $1.77 \%$, and sensitivity of $5.1 \pm 0.2 \times 10^{6}$ ion counts $\min \mu \mathrm{M}^{-1}$. Overall, for products produced with high contents of sugar and extensive heating, such as DL, the quantitation of 5-HMF using the proposed method represents an advantage over previous methods, thanks to the high resolution and sensitivity of LC-HRMS. This confirmed the possibility to directly use 5-HMF as index of the level of the heat treatment in DL. Future works are needed to evaluate the proposed approach with other food products especially those with high levels of 5-HMF formation.

Funding Open access funding provided by Libera Università di Bolzano within the CRUI-CARE Agreement. This research is funded by the FESR-EFRE project Heumilch (FESR1129 CUP: H36H19000000007, EFRE 2014-2020 "Investitionen in Wachstum und Beschäftigung").

\section{Declarations}

Ethical Approval This article does not contain any studies with human or animal subjects.

Informed Consent Informed consent is not applicable.

Conflict of Interest All authors declare no conflict of interest.

Open Access This article is licensed under a Creative Commons Attribution 4.0 International License, which permits use, sharing, adaptation, distribution and reproduction in any medium or format, as long as you give appropriate credit to the original author(s) and the source, provide a link to the Creative Commons licence, and indicate if changes were made. The images or other third party material in this article are included in the article's Creative Commons licence, unless indicated otherwise in a credit line to the material. If material is not included in the article's Creative Commons licence and your intended use is not permitted by statutory regulation or exceeds the permitted use, you will need to obtain permission directly from the copyright holder. To view a copy of this licence, visit http://creativecommons.org/licenses/by/4.0/.

\section{References}

Abraham K, Gürtler R, Berg K, Heinemeyer G, Lampen A, Appel KE (2011) Toxicology and risk assessment of 5-hydroxymethylfurfural in food. Mol Nutr Food Res 55:667-678. https://doi.org/10. 1002/mnfr.201000564

Aktağ IG, Hamzalığlu A, Gökmen V (2019) Lactose hydrolysis and protein fortification pose an increased risk for the formation of Maillard reaction products in UHT treated milk products. J Food Compos Anal 84:103308. https://doi.org/10.1016/j.jfca.2019. 103308

Bellarde FB (2005) [Preparation of pasty dulce de leche with partial replacement of milk solids with whey protein concentrate]. Revista Brasileira Multidisciplinar 9:249. https://doi.org/10. 25061/2527-2675/ReBraM/2006.v9i2.280

Czerwonka M, Pietrzak-Sajjad R, Bobrowska-Korczak B (2020) Evaluation of 5-hydroxymethylfurfural content in market milk products. Food additives and contaminants. Part a, Chemistry, Analysis, Control, Exposure and Risk Assessment 37:1135-1144. https:// doi.org/10.1080/19440049.2020.1757162

Durling LJK, Busk L, Hellman BE (2009) Evaluation of the DNA damaging effect of the heat-induced food toxicant 
5-hydroxymethylfurfural (HMF) in various cell lines with different activities of sulfotransferases. Food Chem Toxicol 47:880 884. https://doi.org/10.1016/j.fct.2009.01.022

Escriche I, Visquert M, Carot JM, Domenech E, Fito P (2008) Effect of honey thermal conditions on hydroxymethylfurfural content prior to pasteurization. Food Sci Technol Int 14:29-35. https://doi.org/ $10.1177 / 1082013208094580$

d'A Francisquini J, Neves LN, Torres JK, Carvalho AF, Perrone IT, da Silva PHF (2018) Physico-chemical and compositional analyses and 5-hydroxymethylfurfural concentration as indicators of thermal treatment intensity in experimental dulce de leche. J Dairy Res 85:476-481. https://doi.org/10.1017/S0022029918000353

d'A Francisquini J, Oliveira LN, Pereira JPF, Stephani R, Perrone ÍT, Silva PHF (2016) Avaliação da intensidade da reação de Maillard, de atributos físico-químicos e análise de textura em doce de leite. Revista Ceres 63:589-596. https://doi.org/10.1590/0034-737x2 01663050001

d'A Francisquini J, Rocha J, Martins E, Stephani R, Fonseca Henrique, da Silva P, Toledo Renhe I, TulerPerrone I, Fernandes de Carvalho A (2019) 5-Hydroxymethylfurfural formation and color change in lactose-hydrolyzed Dulce de leche. Journal of Dairy Research 86:477-482. https://doi.org/10.1017/S0022 029919000815

Garcia-Villanova B, Guerra-Hernandez E, Martinez-Gomez E, Montilla J (1993) Liquid chromatography for the determination of 5-(hydroxymethyl)-2-furaldehyde in breakfast cereals. J Agric Food Chem 41:1254-1255. https://doi.org/10.1021/jf00032a017

Gürkan R, Altunay N (2015) Quantification of 5-hydroxymethylfurfural in honey samples and acidic beverages using spectrophotometry coupled with ultrasonic-assisted cloud point extraction. J Food Compos Anal 42:141-151. https://doi.org/10.1016/j.jfca. 2015.03.012

Haghani-Haghighi H, Mortazavian AM, Hosseini H, Mohammadi A, Shojaee-Aliabadi S, Khosravi-Darani K, Khorshidian N (2019) Method validation and determination of hydroxymethyl furfural (HMF) and furosine as indicators to recognize adulterated cow's pasteurized and sterilized milks made by partial reconstitution of skim milk powder. Biointerface Res Appl Chem 9:3842-3848. https://doi.org/10.33263/BRIAC92.842848

$\mathrm{Hu}$ X, Li CZ (2011) Levulinic esters from the acid-catalysed reactions of sugars and alcohols as part of a bio-refinery. Green Chem 13:1676. https://doi.org/10.1039/c1gc15272f

Jousse F, Jongen T, Agterof W, Russell S, Braat P (2002) Simplified kinetic scheme of flavor formation by the Maillard reaction. J Food Sci 67:2534-2542. https://doi.org/10.1111/j.1365-2621. 2002.tb08772.x

Keeney M, Bassette R (1959) Detection of intermediate compounds in the early stages of browning reaction in milk products 1 . J Dairy Sci 42:945-960. https://doi.org/10.3168/jds.S0022-0302(59) 90678-2

Kowalski S, Lukasiewicz M, Duda-Chodak A, Zięć G (2013) 5-Hydroxymethyl-2-furfural (HMF) - heat-induced formation, occurrence in food and biotransformation - a review. Polish Journal of Food and Nutrition Sciences 63:207-225. https://doi.org/ 10.2478/v10222-012-0082-4

Labuza TP, Baisier WM (1992) The kinetics of nonenzymatic browning. In: Schwartzberg HG, Hartel RW (eds) Physical chemistry of foods. Marcel Dekker Inc, New York, pp 595-649

Larrañaga MD, Lewis RJ, Lewis RA (2016) Hawley's condensed chemical dictionary, Sixteenth. John Wiley and Sons Inc, Hoboken, NJ, USA

Maillard LC (1912) Action des acides amines sur les sucres; formation des melanoidines par voie methodique. Comptes r Acad Sci (paris) 154:66-68

Malec LS, Llosa RA, Naranjo GB, Vigo MS (2005) Loss of available lysine during processing of different dulce de leche formulations.
Int J Dairy Technol 58:164-168. https://doi.org/10.1017/S0022 029999003416

Malec LS, Llosa RA, Vigo MS (1999) Sugar formulation effect on available lysine content of dulce de leche. J Dairy Res 66:335339. https://doi.org/10.1017/S0022029999003416

Morales FJ, van Boekel MAJS (1998) A study on advanced Maillard reaction in heated casein/sugar solutions: colour formation. Int Dairy J 8:907-915. https://doi.org/10.1016/S0958-6946(99) 00014-X

Mundt S, Wedzicha BL (2003) A kinetic model for the glucose-fructose-glycine browning reaction. J Agric Food Chem 51:36513655. https://doi.org/10.1021/jf026027e

Murkovic M, Bornik MA (2007) Formation of 5-hydroxymethyl2-furfural (HMF) and 5-hydroxymethyl-2-furoic acid during roasting of coffee. Mol Nutr Food Res 51:390-394. https://doi. org/10.1002/mnfr.200600251

Murkovic M, Pichler N (2006) Analysis of 5-hydroxymethylfurfual in coffee, dried fruits and urine. Mol Nutr Food Res 50:842846. https://doi.org/10.1002/mnfr.200500262

Nässberger L (1990) Influence of 5-hydroxymethylfurfural (5-HMF) on the overall metabolism of human blood cells. Hum Exp Toxicol 9:211-214. https://doi.org/10.1177/096032719000900402

Newton AE, Fairbanks AJ, Golding M, Andrewes P, Gerrard JA (2012) The role of the Maillard reaction in the formation of flavour compounds in dairy products-not only a deleterious reaction but also a rich source of flavour compounds. Food Funct 3:1231-1241. https://doi.org/10.1039/c2fo30089c

Pavlovic S, Santos R, Glória MBA (1994) Maillard reaction during the processing of 'Doce de leite.' J Sci Food Agric 66:129-132. https://doi.org/10.1002/jsfa.2740660204

Pinto, A and Wolfschoon-Pombo, A (1984) [5-hydroxymethylfurfural in doce de leite]. Revista do Instituto de laticinios Cåndido Tostes 39:9-11

Pischetsrieder M, Groß U, Schoetter C (1999) Detection of Maillard products of lactose in heated or processed milk by HPLC/ DAD. Zeitschrift Fr Lebensmitteluntersuchung Und -Forschung A 208:172-177. https://doi.org/10.1007/s002170050397

Ramírez-Jiménez A, Guerra-Hernández E, García-Villanova B (2000) Browning indicators in bread. J Agric Food Chem 48:4176-4181. https://doi.org/10.1021/jf9907687

Resmini P, Pellegrino L, Battelli G (1990) Accurate quantification of furosine in milk and dairy products by a direct HPLC method. Ital J Food Sci 2:173-183

Resmini P, Pellegrino L, Cattaneo S (2003) Furosine and other heat treatment indicators for detecting fraud in milk and milk products. Ital J Food Sci 15:473-484

Rodriguez A, Cuffia F, Piagentini AM, Lema P, Panizzolo LA, Rozycki SD (2016) Study of the browning and gelation kinetics in a concentrated sheep milk and sucrose system. Int J Dairy Technol 69:1-7. https://doi.org/10.1111/1471-0307.12327

Ritota M, Di Costanzo MG, Mattera M, Manzi P (2017) New trends for the evaluation of heat treatments of milk. J Anal Methods Chem 2017. https://doi.org/10.1155/2017/1864832

Serra-Cayuela A, Castellari M, Bosch-Fusté J, Riu-Aumatell M, Buxaderas S, López-Tamames E (2013) Identification of 5-hydroxymethyl-2-furfural (5-HMF) in Cava sparkling wines by LC-DAD-MS/MS and NMR spectrometry. Food Chem 141:3373-3380. https://doi.org/10.1016/j.foodchem.2013.05. 158

Severin I, Dumont C, Jondeau-Cabaton A, Graillot V, Chagnon MC (2010) Genotoxic activities of the food contaminant 5-hydroxymethylfurfural using different in vitro bioassays. Toxicol Lett 192:189-194. https://doi.org/10.1016/j.toxlet.2009.10.022

Shapla UM, Solayman M, Alam N, Khalil MI, Gan SH (2018) 5-Hydroxymethylfurfural (HMF) levels in honey and other food 
products: effects on bees and human health. Chem Cent J 12:35. https://doi.org/10.1186/s13065-018-0408-3

Teixidó E, Moyano E, Santos FJ, Galceran MT (2008) Liquid chromatography multi-stage mass spectrometry for the analysis of 5-hydroxymethylfurfural in foods. J Chromatogr A 1185:102108. https://doi.org/10.1016/j.chroma.2008.01.057

Teixidó E, Santos FJ, Puignou L, Galceran MT (2006) Analysis of 5-hydroxymethylfurfural in foods by gas chromatography-mass spectrometry. J Chromatogr A 1135:85-90. https://doi.org/10. 1016/j.chroma.2006.09.023

Troise AD (2018) Analytical strategies to depict the fate of the Maillard reaction in foods. Curr Opin Food Sci 19:15-22. https://doi.org/ 10.1016/j.cofs.2017.12.005

Tsai SW, Kao KY (2012) Determination of furfural in beers, vinegars and infant formulas by solid-phase microextraction and gas chromatography/mass spectrometry. Int J Environ Anal Chem 92:76-84. https://doi.org/10.1080/03067319.2010.496050

van Boekel MAJS (2006) Formation of flavour compounds in the Maillard reaction. Biotechnol Adv 24:230-233. https://doi.org/ 10.1016/j.biotechadv.2005.11.004

van Boekel MAJS (1998) Effect of heating on Maillard reactions in milk. Food Chem 62:403-414. https://doi.org/10.1016/S03088146(98)00075-2

Publisher's Note Springer Nature remains neutral with regard to jurisdictional claims in published maps and institutional affiliations. 